\title{
MMA Editor Receives ASM Silver Medal
}

Dr. Ryan M. Deacon, editor-in-chief of Metallography, Microstructure, and Analysis, was awarded the Silver Medal of ASM International at the ASM Awards Dinner during MS\&T 2015 in Columbus, Ohio, in October. Deacon, a materials scientist in the Materials Engineering and Research Group of the DuPont Corporation, located at the Experimental Station in Wilmington, Delaware, was cited "For his leadership in the fields of materials characterization, metallography, and microstructural analysis as well as exemplary volunteer service to ASM International and the profession of materials science and engineering."

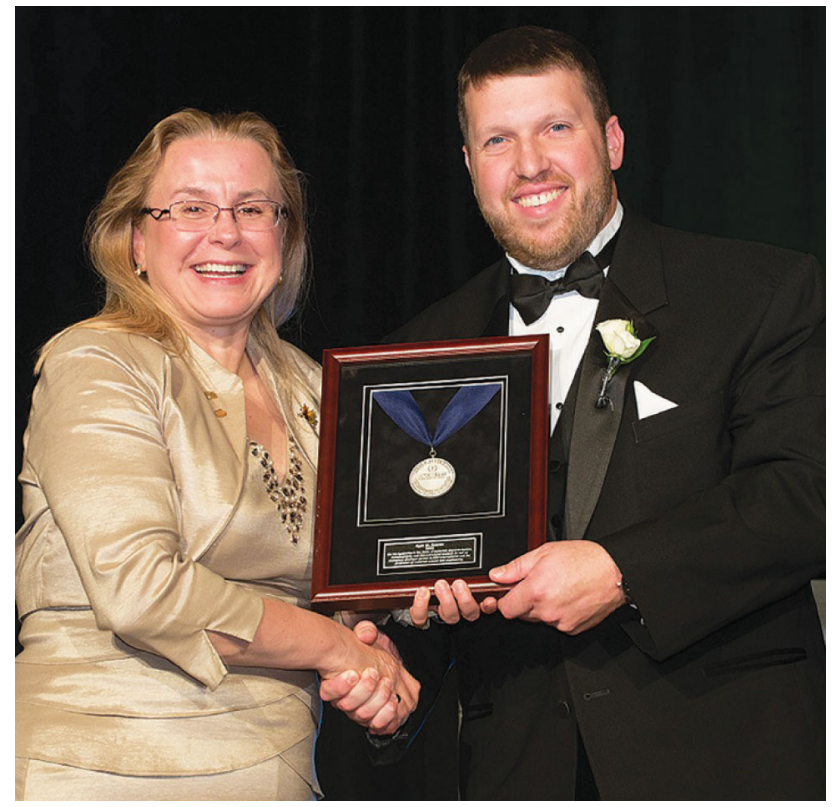

ASM President Sunniva Collins presents the 2015 ASM Silver Medal to Dr. Ryan Deacon at the ASM Awards Dinner during MS\&T'15 in Columbus, Ohio.
Established in 2010, the honor of Silver Medal of the Society is to provide recognition to members who are in midcareer positions (typically 5 to 15 years of experience) for distinguished contributions in the field of materials science and engineering and to the Society. The purpose of this award is to recognize leadership at an early stage and encourage individuals to grow, nurture, and further contribute to the growth of the profession as well as the Society.

Deacon serves as the corporate failure analyst for DuPont, conducting failure investigations and material analyses for all of the DuPont businesses. Prior to joining DuPont, he was a senior professional staff member at the Johns Hopkins University Applied Physics Laboratory (JHUAPL), where he worked in both the technical services and the research and development departments. While at JHUAPL, he oversaw the laboratory's metallography and microscopy facilities, and participated in a number of research programs related to materials characterization and development. He has authored and co-authored a number of publications in the fields of corrosion and materials characterization, and is a recipient of the Jacquet-Lucas Award for Excellence in Metallography.

Deacon earned B.S., M.S., and Ph.D. degrees in materials science and engineering from Lehigh University. Since beginning his participation with ASM as an undergraduate, he has held a number of volunteer positions within the Society. He served the Lehigh Valley Chapter in numerous executive board positions and was a recipient of the chapter's Outstanding Young Member Award. On the national level, he was a member of the Emerging Professionals Committee, the Membership Committee, and the Material Advantage Committee, and in 2013, was chair of the Chapter Council. In October 2015, he became a trustee of the Society. He currently serves on the executive committee of the Brandywine Valley (Pennsylvania) Chapter. 